\title{
HEAT CAPACITY, ENTROPY, AND FREE ENERGY OF RUBBER HYDROCARBON
}

\author{
By Norman Bekkedahl and Harry Matheson
}

\begin{abstract}
Measurements of heat capacity were made on rubber hydrocarbon in its different forms from 14 to $320^{\circ} \mathrm{K}$ with an adiabatic vacuum-type calorimeter. At $14^{\circ} \mathrm{K}$ the heat capacity was found to be $0.064 \mathrm{j} / \mathrm{g} /{ }^{\circ} \mathrm{C}$ for both the metastable amorphous and the crystalline forms. With increase in temperature, the heat capacity increases gradually up to a transition at about $199^{\circ} \mathrm{K}$, the amorphous form having a little the greater value. At $199^{\circ} \mathrm{K}$ both forms undergo a transition of the second order, the heat capacity rising sharply. For the amorphous form above this transition the heat capacity rises gradually without discontinuity to the highest temperature of the measurements. The crystalline form undergoes fusion (a transition of the first order) at $284^{\circ} \mathrm{K}$, the heat of fusion being 16.7 $\mathrm{j} / \mathrm{g}$. At $298.1^{\circ} \mathrm{K}$ the heat capacity of the rubber is $1.880 \pm 0.002 \mathrm{j} / \mathrm{g} /{ }^{\circ} \mathrm{C}$. Utilization of the data according to the third law of thermodynamies yields $1.881 \pm$ $0.010 \mathrm{j} / \mathrm{g} /{ }^{\circ} \mathrm{C}$ for the entropy of rubber at $298.1^{\circ} \mathrm{K}$. Combination of these with appropriate other data on entropies and heats of reaction yields $1.35 \pm 0.10$ $\mathrm{kj} / \mathrm{g}$ for the standard free energy of formation at $298.1^{\circ} \mathrm{K}$ of rubber from carbon (graphite) and gaseous hydrogen.
\end{abstract}

\section{CONTENTS}

I. Introduction

503

II. Rubber sample investigated

504

III. Calorimeter and its operation

IV. Heat capacities

506

V. Heat of fusion

VI. Entropy

VII. Free energy of formation

VIII. References

\section{INTRODUCTION}

The best method for obtaining the free energy of formation of rubber is by making use of the third law of thermodynamics. This makes necessary the determination of heat-capacity values of the rubber in the temperature range from that of room down to temperatures sufficiently low to apply an empirical formula for obtaining the values below this lower temperature. From these heat-capacity values the entropy may be obtained. Then from this latter value, along with the entropy values of carbon (graphite) and gaseous hydrogen and the heat of formation of rubber, a reliable value for the free energy of formation of rubber may be calculated.

Several investigators have previously determined the heat capacities of rubber, but their observations were not made at temperatures 
sufficiently low to permit accurate extrapolation to the absolute zero in order to apply the third law. Furthermore, in the previous work the possibility that rubber at low temperatures might exist either as a metastable amorphous form or as a crystalline form was not clearly recognized. In the present investigation the aim was not only to extend the temperature range but also to obtain data of a higher order of accuracy than that previously reported.

\section{RUBBER SAMPLE INVESTIGATED}

The sample of rubber used in this investigation was prepared by the digestion of latex with steam at about $190^{\circ} \mathrm{C}$ and the subsequent extraction of the resins and the products of hydrolysis with alcohol and water [20]. ${ }^{1}$ Where the term rubber or rubber hydrocarbon is used without qualification in this paper, the foregoing product is understood. The sample, of mass $38.30 \mathrm{~g}$, was cut into small pieces, roughly $10 \mathrm{~mm}^{3}$ each, before its introduction into the calorimeter. At that time it gave no indication of any oxidation having taken place. The air surrounding the rubber in the calorimeter container was replaced by helium so there would be no oxidation.

A complete set of values for the heat capacity of the amorphous form of rubber from 14 to $320^{\circ} \mathrm{K}$ and several values for the crystalline form were obtained within the first several months. During this time the sample container of the calorimeter can remained gastight and no oxidation of the rubber sample could have taken place. However, owing to a forced delay, no further measurements were made with the calorimeter for nearly two years, during which time the calorimeter can developed a leak and the helium was displaced by air. Oxidation of the sample was rapid, and by the time it was removed from the container it had a strong odor of oxidation products and had increased its weight to $39.38 \mathrm{~g}$. The increase in mass was about 2.8 percent, and, if due to oxygen alone, would give an approximate empirical formula $\mathrm{C}_{5} \mathrm{H}_{8} \mathrm{O}_{0.1}$ instead of $\mathrm{C}_{5} \mathrm{H}_{8}$. During the several weeks previous to the removal of the sample from the calorimeter, a complete set of measurements was made on the crystalline form from 14 to $320^{\circ} \mathrm{K}$ and several measurements were repeated on the amorphous form. The air was pumped from the sample container during these observations, so it was assumed that this final weight of the sample was constant during these later runs. The larger mass was used for the calculations of the results of the latter experiments, while the original mass was used in the calculation of the results of the experiments performed two years before. When calculated in this manner, the heat capacity of the rubber after this oxidation had occurred appeared unchanged, within 0.2 percent, from its value before oxidation, the results on both forms at different temperatures showing no consistent deviation from the earlier values. This seems to indicate that the oxidation had no significant effect on the value of the heat capacity of the rubber as determined in these experiments. ${ }^{2}$

\footnotetext{
1 The numbers in brackets here and elsewhere in the text refer to the "References" at the end of this paper.

${ }_{2}$ These results indicate, however, that at room temperature the oxygen taken up by the rubber must have a heat capacity contribution of about 7 cal per oxygen a tom if the addition causes no change in the heat capacity per gram of total sample. This value of 7 cal is considerably larger than that usually derived from organic compounds by Kopp's rule.
} 
It was not necessary to remove the sample from the container in order to convert it from one form to another. The procedure for obtaining the crystalline form of rubber was to cool the calorimeter to about $-40^{\circ} \mathrm{C}$, allow it to warm up slowly over a period of several days to $0^{\circ} \mathrm{C}$, and then to hold it at this latter temperature for several more days. Previous work [3] has indicated that this is sufficient time to obtain complete conversion into the crystalline form. Incomplete conversion would liberate heat in the temperature range from -40 to $0^{\circ} \mathrm{C}$, which would easily be noticed from the behavior of the calorimeter during the heat-capacity measurements, as was actually found to be the case on several occasions.

\section{CALORIMETER AND ITS OPERATION}

The calorimeter used for the measurements of the heat capacities and the heat of transition was of the adiabatic and vacuum type described by Southard and Brickwedde [33], which is an improvement on the type originated by Eucken [8]. The object of the vacuum surrounding the sample container is to minimize the exchange of heat between the container and its surroundings as caused by gaseous conduction and convection. The calorimeter was made adiabatic by surrounding the sample container with a shield which, by means of controlled electrical heating, could be kept the same temperature as the sample, thus minimizing heat leakages to and from the sample. The calorimeter is described in detail by Southard and Brickwedde and only a few general statements need be made here. After the introduction of the sample into its container, the remaining air in the container was replaced by helium at about 1 atmosphere pressure before the container was sealed. Air could not be left inside because it would permit oxidation of the rubber and also because it would liquefy at low temperatures. A vacuum in place of the helium would not be as suitable because the lack of thermal conducting qualities would necessitate too long a time for the sample to reach temperature equilibrium, which was found to be the case in the latter experiments.

Measurements of temperature were made by means of a resistance thermometer of platinum containing 10 percent of rhodium, the resistance of which was about $150 \mathrm{ohms}$ at room temperature. From 14 to $90^{\circ} \mathrm{K}$ its calibration was made against a helium gas thermometer described by Southard and Milner [34]. Above $90^{\circ} \mathrm{K}$ it was calibrated against a standard platinum resistance thermometer in a precision cryostat designed and built by Scott and Brickwedde [30]. Resistances were measured by means of a Wenner potentiometer $[2,37]$, potentials being obtained across the thermometer and also across a $100-0 \mathrm{hm}$ standard coil in series with the thermometer when a current of about 1 milliampere was passing through the circuit. This current was supplied by a 2 -volt lead storage battery. The precision of the temperature measurements was within $0.002^{\circ} \mathrm{C}$ above $90^{\circ} \mathrm{K}$ and within $0.01^{\circ} \mathrm{C}$ at lower temperatures.

This thermometer was also used as a heater. The current and voltage during the heating were also measured with the same potentiometer, using a 1-ohm standard resistance coil and a volt-box with a ratio of 150:1. Lead storage cells of 120 volts were the source of the heating current. The time of heating was regulated by an automatic switch connected to time signals, which gave a measure of time to 
within 0.01 second. The time of heating was varied from 5 to 30 minutes, the heating current from 0.03 to 0.1 ampere, and the temperature from 0.5 to about $15^{\circ} \mathrm{C}$. The amount of heat added could be measured to within 1 part in 10,000, which is greater precision than is necessary, since the temperature rise could sometimes be measured only to about 1 part in 1,000. It was not found difficult to control the shields so that the sample would remain constant in temperature within $0.002^{\circ} \mathrm{C}$ for an hour, even when its temperature was many degrees above that of the surrounding external bath. An actual test of the heat exchange to and from the sample was made with an external bath of liquid hydrogen at about $20^{\circ} \mathrm{K}$, the sample and its container at about $90^{\circ} \mathrm{K}$, with the shields a little more than a degree higher. Here the temperature of the sample rose $0.15^{\circ} \mathrm{C}$ per hour. With the shields only $0.4^{\circ} \mathrm{C}$ higher, the rate of temperature rise was $0.04^{\circ} \mathrm{C}$ per hour. In actual operation of the calorimeter, the temperature of the shields was kept within $0.01^{\circ} \mathrm{C}$ of that of the sample, and these deviations were not consistent in either direction but tended to balance each other.

Two operators were necessary for conducting experiments with the calorimeter. One made the measurements on the temperature of and the heat energy added to the sample and container, while the other controlled the temperatures of the shields. The latter was done by regulating the current flowing through the heating wires of the shields. After the sample had shown a constant temperature over a period of several minutes, the electrical switch was thrown for the addition of heat. This necessitated a corresponding increase in the quantity of heat to the shields in order to maintain them at the temperature of the sample. The heat to the shields, of course, was not measured. The heat delivered to the sample was determined from current and voltage readings made at definite time intervals. When the heating interval was complete the automatic switch was again thrown, this time to stop the heating current. When temperature equilibrium was again established, which generally took from 5 to 10 minutes, the temperature was again measured, and then another heating period started. During these heating periods resistances of the current leads from the heater to the shield were measured. The assumption was made that half the heat produced in these leads went to the sample and container and the other half to the shields. Corrections for this additional current were found to be about 3 parts in 10,000 at room temperature and less at lower temperatures.

\section{HEAT CAPACITIES}

The curves in figures 1 and 2 give the relation between heat capacity and temperature, the solid line indicating the amorphous form of rubber and the broken line the crystalline form. The curve is shown in sections so that a larger scale may be used. Figure 3 gives the same curves on a smaller scale, the only points of observation shown being those in the transition range, which are not indicated in figures 1 and 2 because of the scale used. Table 1 gives the heatcapacity values at $5^{\circ}$ intervals obtained from the curve. All quantities of heat in this paper are expressed in international joules. The factor for conversion into cal ${ }_{15}$ is 4.1833 [25]. 
TABLE 1.-Heat capacities of the rubber hydrocarbon

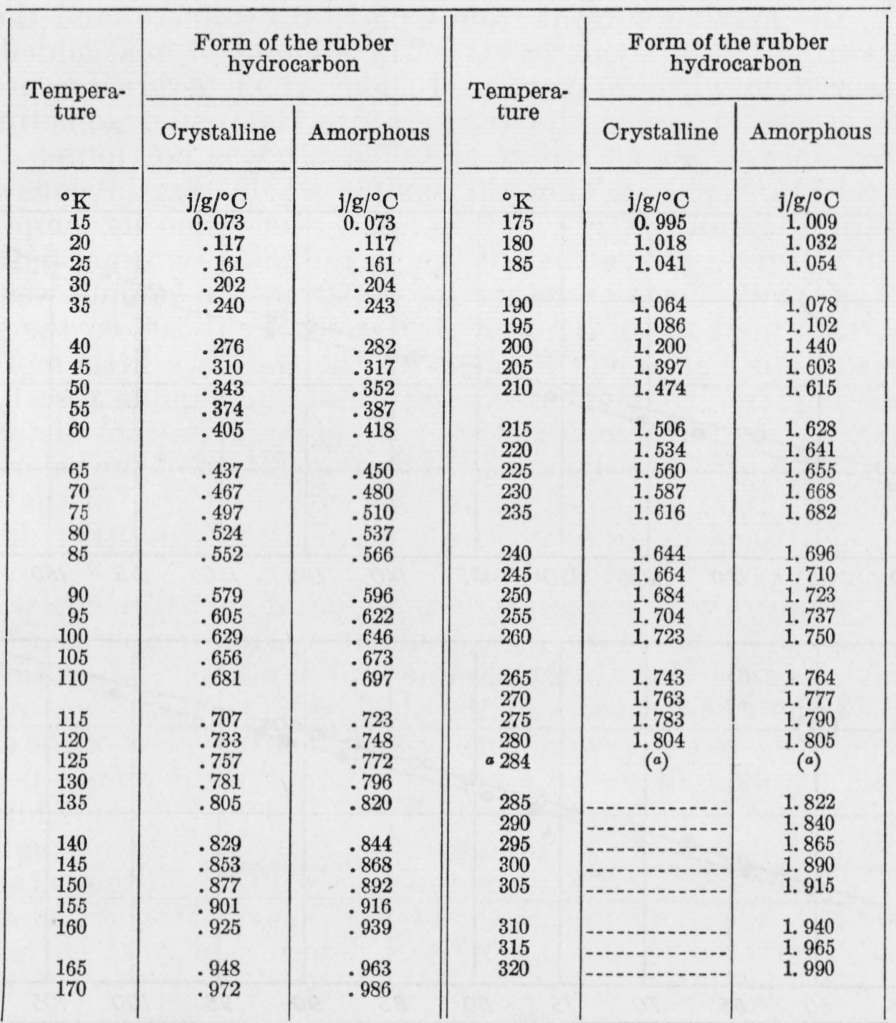

a Heat of fusion at $284^{\circ} \mathrm{K}$ is $16.7 \mathrm{j} / \mathrm{g}$.

With the exception of the range of temperature where the crystals are melting, the heat capacities of the crystalline form of rubber are in general lower than those of the amorphous form. This is to be expected because of less randomness of the positions of the molecules in the crystalline form.

Tables 2 and 3 give the data and results of the calculation of one observation on the heat capacity of the crystalline form of the rubber hydrocarbon. Current reversals were made and the values obtained in the two directions were averaged in order to compensate for any stray currents which may have been present in the system. The mean temperature and the rise in temperature were obtained directly from the data in table 2. In order to obtain the amount of heat added, the values of the current passing through the heater and also the potential across the heater (table 3 ) were plotted as a function of time, and the values at the half-period of heating (6.5 minutes) were taken as the average. Both the current and the voltage show straight-line relationships with time over short intervals such as this unless the sample is undergoing a transition, in which case there will appear a change of slope of the voltage curve with time. 

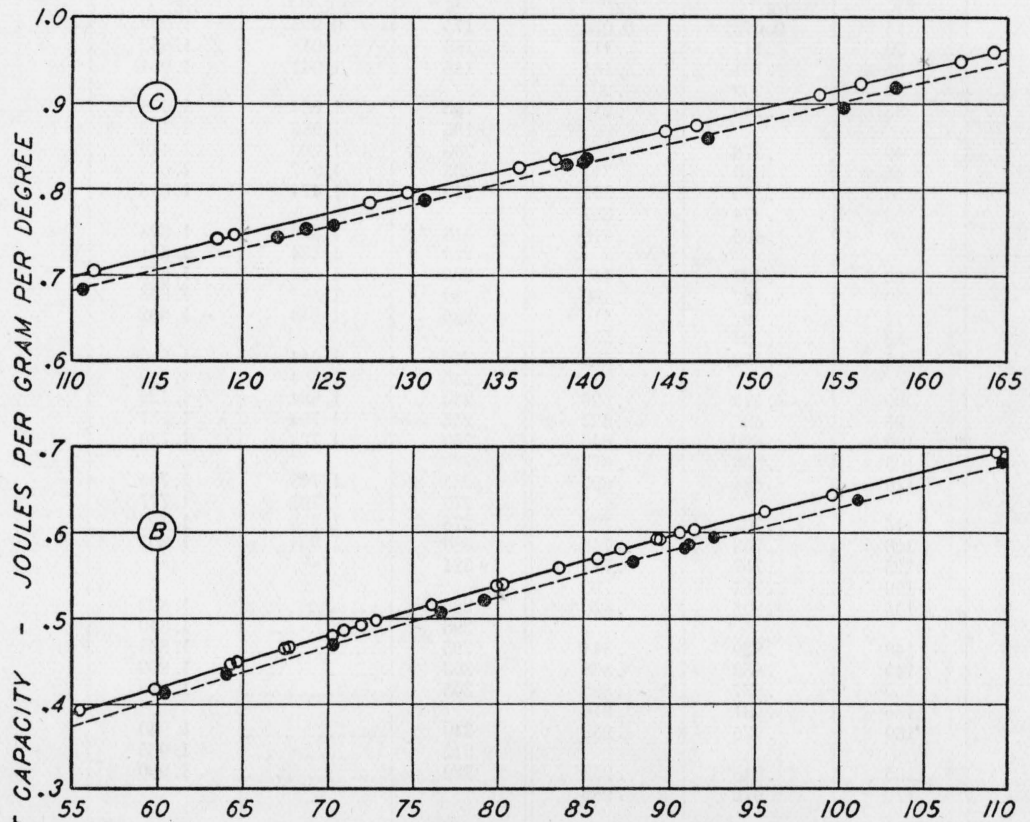

खे

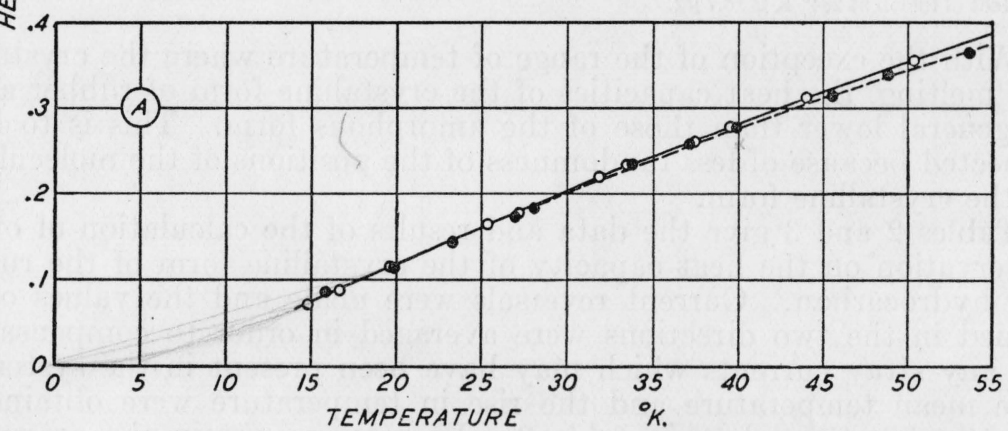

FigURE 1.-Relation between heat capacity of rubber hydrocarbon and temperature. The dotted line represents the crystalline form and the solid line the amorphous. (See fig. 2 for other half of curve.) 

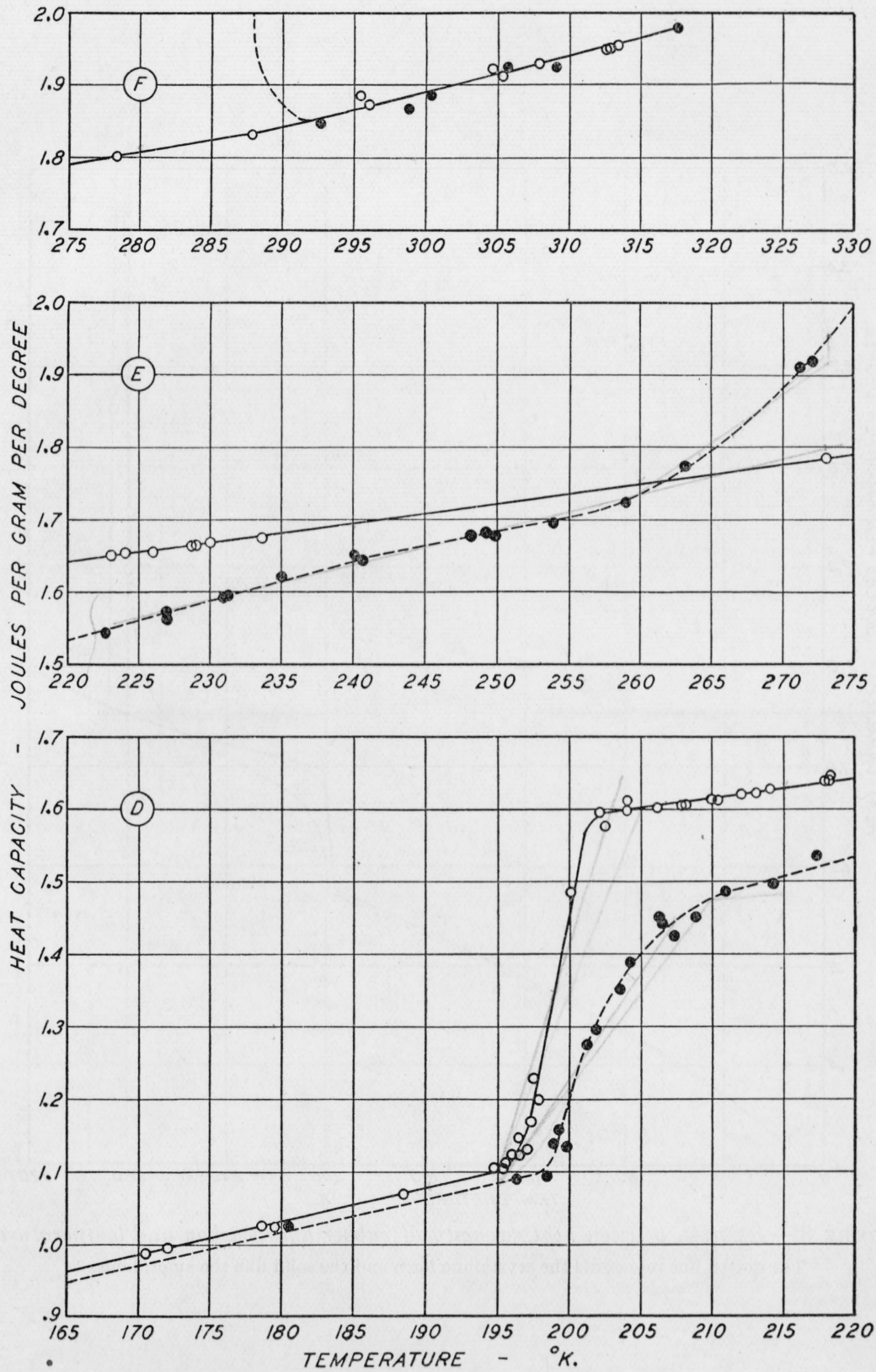

FIGURE 2.-Relation between heat capacity of rubber hydrocarbon and temperature.

The dotted line represents the crystalline form and the solid line the amorphous. (See fig. 1 for other half of curve.) 


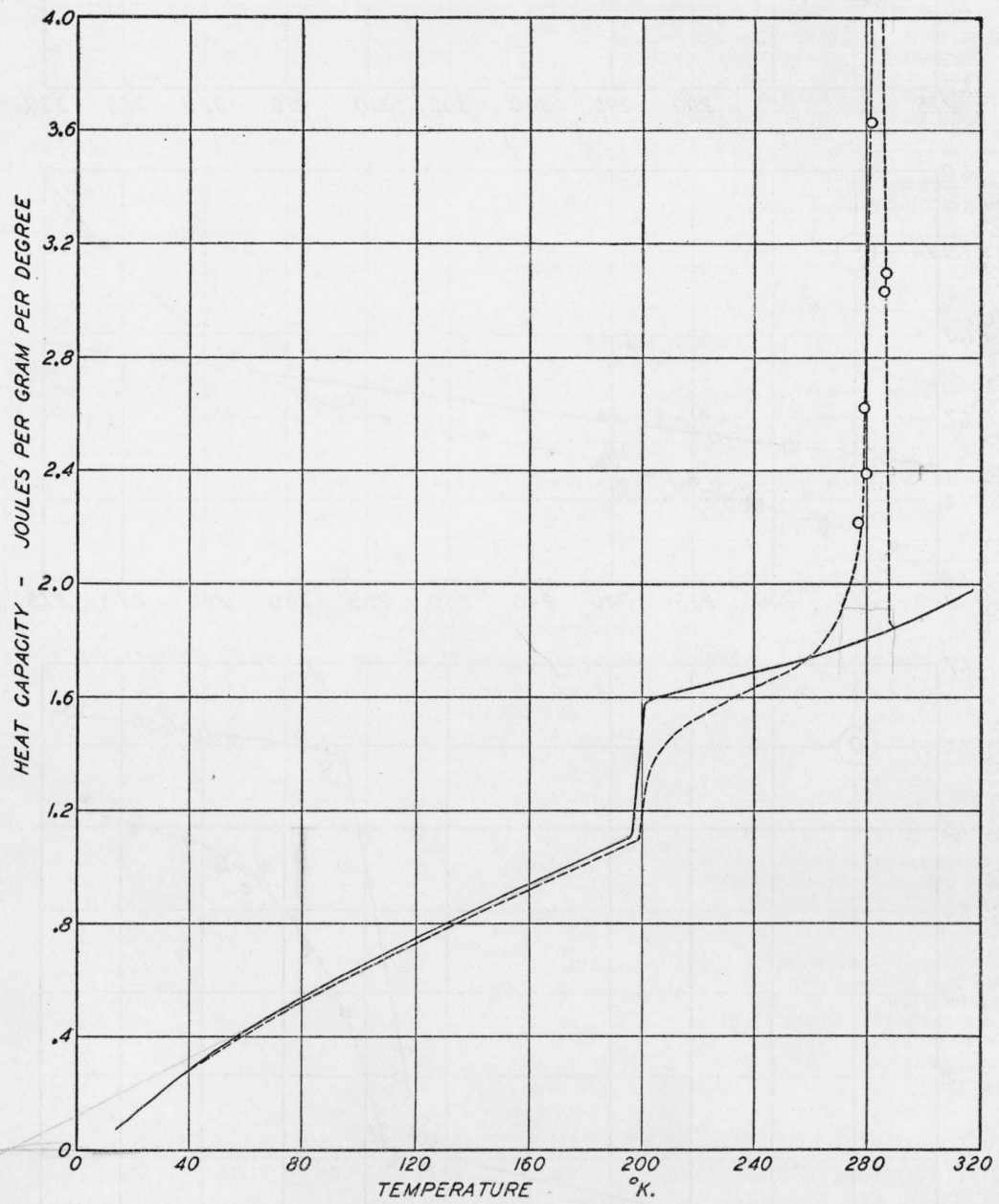

FIGURE 3.-Relation between heat capacity of rubber hydrocarbon and temperature. The dotted line represents the crystalline form and the solid line the amorphous. 
about $1.2 \mathrm{j} / \mathrm{g} /{ }^{\circ} \mathrm{C}$ as compared with 1.09 for that temperature as indicated in figure 2. In an earlier investigation on the heat of vulcanization of rubber [21], mean heat-capacity values were obtained between 25 and $175^{\circ} \mathrm{C}$. The average mean value obtained for both crude and purified rubber was $2.17 \mathrm{j} / \mathrm{g} /{ }^{\circ} \mathrm{C}$, which seems quite reasonable from the trend of the curve of the present investigation.

The curve obtained by Ruhemann and Simon for the heat capacities of smoked sheet from -100 to about $-20^{\circ} \mathrm{C}$, which includes a transition of the second order [3, 7], which they called the $a$ anomaly, is similar to the one obtained in the present investigation. At $0^{\circ} \mathrm{C}$ they obtained a hump in the curve which they called the $\beta$ anomaly, but this break in the curve could not be found in the present investigation. Figure 3 shows that at $284^{\circ} \mathrm{K}$ a transition of the first order takes place in which there is melting of rubber crystals. This transition was named the $\gamma$ anomaly by Ruhemann and Simon, but was found by them to take place at a temperature several degrees higher.

The transition obtained at $199^{\circ} \mathrm{K}$ in this investigation is probably the same as that shown in some previous work on the thermal expansion and dielectric constant of rubber [3], and there reported to take place at approximately $200^{\circ} \mathrm{K}$. The temperature of fusion obtained in the present investigation also agrees with that obtained from data on the coefficient of thermal expansion.

\section{HEAT OF FUSION}

At above $255^{\circ} \mathrm{K}$ the curve for the heat capacity of the crystalline form begins to rise, owing to the premelting of some of the crystals. Although the fusion temperature is $284^{\circ} \mathrm{K}$, there is a great tendency for the rubber to premelt with respect to the average temperature of the calorimeter. The higher local temperature near the heating coil produces a small amount of melting which does not reverse itself when temperature equilibrium is established below the fusion temperature, because the rate of transition from the crystalline to the amorphous form is much greater than that in the reverse direction [3]. This, however, will have no appreciable effect on the value obtained for the heat of melting.

With the rubber in the crystalline form a heating was begun at a temperature of $253.73^{\circ} \mathrm{K}$, continued through the transition, and ended with an equilibrium temperature of $291.90^{\circ} \mathrm{K}$. The heat required to raise the rubber through this temperature range was $102.605 \mathrm{j} / \mathrm{g}$. On the heat capacity-temperature diagram, a smooth curve was drawn from some point on the curve of the crystalline form just below the beginning of the melting of the rubber (about $250^{\circ} \mathrm{K}$ ) to the curve above the temperature of the transition. The energy required to bring the rubber from 253.73 to $291.90^{\circ} \mathrm{K}$, assuming no transition, was obtained by measuring the area under this curve between these two temperatures, and was found to be $85.894 \mathrm{j} / \mathrm{g}$. The difference between these two energy values in $16.71 \mathrm{j} / \mathrm{g}$, which is the heat of fusion of the rubber. This value is in agreement with that obtained in a similar manner by Ruhemann and Simon [29] for frozen smoked sheet. Van Rossem and Loticius [35] report a value of $21.1 \mathrm{j} / \mathrm{g}$ for latex sheet at $0^{\circ} \mathrm{C}$, obtained from the difference between the heats of swelling of frozen and thawed rubber. 


\section{ENTROPY}

According to the third law of thermodynamics, the entropy of a substance in the liquid state at $298.1^{\circ} \mathrm{K}$ is given by the equation

$$
S^{0}{ }_{298.1}=\int_{0}^{T_{\mathrm{mp}}} C_{p} \text { (crystals) } d \ln T+\frac{\Delta H_{\text {fuston }}}{T_{\mathrm{mp}}}+\int_{T_{\mathrm{mp}}}^{298.1} C_{p} \text { (liquid) } d \ln T .
$$

Curves were prepared plotting the values of the heat capacities at constant pressure, $C_{p}$, of the rubber hydrocarbon both in the crystalline and the amorphous forms as functions of the logarithm of the absolute temperature $T$. Since $C_{p}$ values were obtained only as low as $14^{\circ} \mathrm{K}$, the graphic integration of these curves could not be made below this point. Here the Debye approximation formula [6] was used. From tables [31] of the heat capacities and Debye functions, $\beta \nu$, the latter was found to be constant with a value of 120 from 14 to $35^{\circ} \mathrm{K}$. From tables [31] of the Debye functions and entropies with a $\beta \nu$ value of 120 , the entropy change of the rubber from 0 to $14^{\circ} \mathrm{K}$, $\int_{0}^{14} C_{p} d \ln T$, was found to be $0.015 \pm 0.001 \mathrm{j} / \mathrm{g} /{ }^{\circ} \mathrm{C}$ for both the amorphous and the crystalline forms.

From the graphic integration of the curves the following values were obtained:

$$
\begin{aligned}
& \int_{14}^{298.1} C_{p} d \ln T \text { (amorphous form) }=1.860 \mathrm{j} / \mathrm{g} /{ }^{\circ} \mathrm{C}, \\
& \int_{14}^{284} C_{p} d \ln T \text { (crystalline form) }=1.717 \mathrm{j} / \mathrm{g} /{ }^{\circ} \mathrm{C}, \\
& \int_{284}^{298.1} C_{p} d \ln T \text { (amorphous form) }=0.090 \mathrm{j} / \mathrm{g} /{ }^{\circ} \mathrm{C} .
\end{aligned}
$$

The entropy of fusion of the crystalline form of rubber at $284^{\circ} \mathrm{K}$,

$$
\frac{\Delta H_{284}(\text { fusion })}{T}=0.059 \mathrm{j} / \mathrm{g} /{ }^{\circ} \mathrm{C} \text {. }
$$

Following the curve for the amorphous form, one obtains

$$
S_{298.1}-S_{0}=\int_{0}^{14} C_{p} d \ln T+\int_{14}^{298.1} C_{p} d \ln T=1.875 \pm 0.004 \mathrm{j} / \mathrm{g} /{ }^{\circ} \mathrm{C} .
$$

From the data on the crystalline form one obtains

$$
\begin{gathered}
S_{298.1}-S_{0}=\int_{0}^{14} C_{p} d \ln T+\int_{14}^{284} C_{p} d \ln T+\frac{\Delta H_{284} \text { (fusion) }}{T} \\
+\int_{284}^{298.1} C_{p} d \ln T=1.881 \pm 0.010 \mathrm{j} / \mathrm{g} /{ }^{\circ} \mathrm{C}
\end{gathered}
$$

The third law of thermodynamics states that a pure substance in the crystalline state has zero entropy at the absolute zero of temperature. Any other form may not have zero entropy, as has been found by several investigators $[11,16,17,23,24,32]$. The entropy of rubber at $298.1^{\circ} \mathrm{K}$ is obtained from the last equation by setting the entropy 
of the crystalline form equal to zero at $0^{\circ} \mathrm{K}$. Then for rubber at $298.1^{\circ} \mathrm{K}, S_{298.1}=1.881 \pm 0.010 \mathrm{j} / \mathrm{g} /{ }^{\circ} \mathrm{C} .^{3}$

The above data give for the difference between the entropies for the crystalline and amorphous forms at $0^{\circ} \mathrm{K}$ the value $(1.881 \pm 0.010)-$ $(1.875 \pm 0.004)=0.006 \pm 0.011 \mathrm{j} / \mathrm{g} /{ }^{\circ} \mathrm{C}$. This indicates, within the accuracy of the present experimental data, that $S_{0}$ (amorphous)$S_{0}$ (crystalline) is not greater than $0.017 \mathrm{j} / \mathrm{g} /{ }^{\circ} \mathrm{C}$, or $0.28 \mathrm{cal} /{ }^{\circ} \mathrm{C} / \mathrm{C}_{5} \mathrm{H}_{8}$ unit.

\section{FREE ENERGY OF FORMATION}

Various investigators $[4,12,15,18,22,36]$ have determined the heat of combustion of rubber, but the results of Jessup and Cummings [15] are probably the most nearly accurate. Their value for steampurified rubber at $30^{\circ} \mathrm{C}$ is $45,239 \pm 90$ int. $\mathrm{j} / \mathrm{g}$. Using the values of specific heats of $1.89 \mathrm{j} / \mathrm{g} /{ }^{\circ} \mathrm{C}$ for rubber at $27.5^{\circ} \mathrm{C}$ as determined in this investigation, $8.9 \mathrm{cal} / \mathrm{mole} /{ }^{\circ} \mathrm{C}$ for $\mathrm{CO}_{2}[13], 7.0 \mathrm{cal} / \mathrm{mole} /{ }^{\circ} \mathrm{C}$ for $\mathrm{O}_{2}$, and $17.5 \mathrm{cal} / \mathrm{mole} /{ }^{\circ} \mathrm{C}$ for $\mathrm{H}_{2} \mathrm{O}$ [1], the heat of combustion of the rubber hydrocarbon at $298.1^{\circ} \mathrm{K}$ is calculated to be $45,250 \pm 90$ int. j/g.

Using the heats of formation at $298.1^{\circ} \mathrm{K}$ of gaseous $\mathrm{CO}_{2}$ taken as $-94.24 \pm 0.10 \mathrm{kcal} / \mathrm{mole}[28,27]$ and of liquid $\mathrm{H}_{2} \mathrm{O}-68.313 \pm 0.010$ $\mathrm{kcal} / \mathrm{mole}$ [26], the heat of formation of the rubber from its elements, $\Delta \mathrm{H}_{298,1}$ is $-507 \pm 100 \mathrm{j} / \mathrm{g}$. Likewise, from the entropies of carbon (graphite) taken as $1.36 \pm 0.03 \mathrm{cal} / \mathrm{mole} /{ }^{\circ} \mathrm{C}$ [14] and $\mathrm{H}_{2} 31.23 \pm 0.00$ $\mathrm{cal} / \mathrm{mole} /{ }^{\circ} \mathrm{C}[10]$, the entropy of formation of the rubber hydrocarbon at $298.1^{\circ} \mathrm{K}, \Delta S_{298.1}$, is $-6.215 \pm 0.014 \mathrm{j} / \mathrm{g} /{ }^{\circ} \mathrm{C}$. Then, from the thermodynamic formula $\Delta F=\Delta H-T \Delta S$, the thermodynamic potential or free energy of formation of the rubber hydrocarbon at $298.1^{\circ} \mathrm{K}$, $\Delta F_{298.1}=(-507 \pm 100)-(298.1)(-6.215 \pm 0.014)=1,345 \pm 100 \mathrm{j} / \mathrm{g}$, or $1.35 \pm 0.10 \mathrm{kj} / \mathrm{g}$, or $21.9 \pm 1.6 \mathrm{kcal} / \mathrm{C}_{5} \mathrm{H}_{8}$ unit.

The authors wish to express their appreciation to various members of the Bureau staff: to A. T. McPherson and F. G. Brickwedde, under whose supervision this investigation was made; to the members of the latter's staff of the cryogenic laboratory for constructing and assisting in the calibration of the thermometer, and for furnishing the liquid hydrogen; and to W. L. Holt for assisting in making some of the measurements.

\section{REFERENCES}

[1] Awbery, Int. Crit. Tables, 5, 113 (McGraw-Hill Book Co., Inc., New York, N. Y., 1929).

[2] Behr, Rev. Sci. Instr. 3, 109 (1932).

[3] Bekkedahl, J. Research NBS 13, 441 (1934) RP717. Reprinted in Rubber Chem. Tech. 8, 5 (1935).

[4] Blake, Ind. Eng. Chem. 22, 737 (1930).

[5] Bostörm, Kolloidchem. Beihefte 26, 439 (1928).

[6] Debye, Ann. Physik [4] 39, 789 (1912).

[7] Ehrenfest, Koninklijke Akad. Wetenschappen Amsterdam 36, 153 (1933).

[8] Eucken, Physik. Z. 10, 586 (1909).

${ }^{3} \mathrm{It}$ is of interest to note here that from a calculation of the entropy of the rubber hydrocarbon at $298.1^{\circ} \mathrm{K}$ from a table on page 210 of Parks and Huffman's "The Free Energy of Some Organic Compounds" (Chemical Catalog Co., Inc., New York, N. Y.), a value of $1.92 \mathrm{j} / \mathrm{g} /{ }^{\circ} \mathrm{C}$ is obtained. This assumes a long chain rubber molecule having $1 \mathrm{CH}_{3}$ branch chain and 1 double bond per $\mathrm{C}_{3} \mathrm{H}_{8}$ unit. 
[9] Gee and Terry, Brit. Assn. Advancement Sci. Rep. page 516 (1889). Also Mem. Proc. Manchester Lit. Phil. Soc. [4] 4, 38 (1891).

[10] Giauque, J. Am. Chem. Soc. 52, 4816 (1930).

[11] Gibson and Giauque, J. Am. Chem. Soc. 45, 93 (1923).

[12] Hada, Fukaya, and Nakajima, J. Rubber Soc. Japan 2, 389 (1931). Translated in Rubber Chem. Tech. 4, 507 (1931).

[13] Holborn and Henning, Ann. Physik 23, 809 (1907).

[14] Jacobs and Parks, J. Am. Chem. Soc. 56, 1513 (1934).

[15] Jessup and Cummings, J. Research NBS 13, 357 (1934) RP713. Reprinted in Rubber Chem. Tech. 8, 44 (1935).

[16] Kelley, J. Am. Chem. Soc. 51, 779 (1929).

[17] Kelley, J. Am. Chem. Soc. 51, 1400 (1929).

[18] Kirchhof and Matulke, Ber. deut. chem. Ges. 5\%B, 1266 (1924).

[19] LeBlanc and Kröger, Z. Elektrochem. 34, 241 (1928).

[20] McPherson, BS J. Research 8, 751 (1932) RP449. Reprinted in Rubber Chem. Tech. 5, 523 (1932).

[21] McPherson and Bekkedahl, J. Research NBS 14, 601 (1935) RP791. Reprinted in Rubber Chem. Tech. 8, 456 (1935).

[22] Messenger, Inst. Rubber Ind. 5, 71 (1929). Reprinted in Rubber Chem. Tech. 3, 24 (1930).

[23] Parks and Huffman, J. Am. Chem. Soc. 48, 2788 (1926).

[24] Pauling and Tolman, J. Am. Chem. Soc. 4\%, 2148 (1925).

[25] Rossini, BS J. Research, 9, 679 (1932) RP499.

[26] Rossini, BS J. Research 6, 1 (1931) RP259.

[27] Rossini, BS J. Research 13, 21 (1934) RP692.

[28] Roth and Naeser, Z. Elektrochem. 31, 461 (1925).

[29] Ruhemann and Simon, Z. physik. Chem. 138A, 1 (1928).

[30] Scott and Brickwedde, BS J. Research 6, 401 (1931) RP284.

[31] Simon, Handbuch der Physik, 10, p. 367.

[32] Simon and Lange, Z. Physik 38, 227 (1926).

[33] Southard and Brickwedde, J. Am. Chem. Soc. 55, 4378 (1933).

[34] Southard and Milner, J. Am. Chem. Soc. 55, 4384 (1933).

[35] Van Rossem and Loticius, Kautschuk 5, 2 (1929). Translated in Rubber Chem. Tech. 2, 378 (1929).

[36] Weber, The Chemistry of India Rubber, page 107 (Charles Griffin and Co., Ltd., London, 1902).

[37] Wenner, Phys. Rev. 31, 94 (1910).

Washington, September 26, 1935. 